\title{
"ISSO É AULA DE EDUCAÇÃO FÍSICA?" PRÁTICAS CORPORAIS NA ESCOLA
}

\author{
Leiriane Viveiros Gregório \\ Universidade de Brasília, Distrito Federal, Brasil. \\ Ingrid Dittrich Wiggers \\ Universidade de Brasília, Distrito Federal, Brasil. \\ Dulce Filgueira de Almeida \\ Universidade de Brasília, Distrito Federal, Brasil.
}

\begin{abstract}
Resumo
O trabalho objetiva analisar as "práticas corporais" como tema da educação física, por meio da proposição e discussão de um projeto pedagógico, junto a uma turma de oitavo ano de uma escola pública do Distrito Federal. O estudo valeu-se da problematização e vivência de esporte, dança e brincadeiras populares, à luz do conceito de "práticas corporais". O desenho metodológico foi pautado em elementos da pesquisa pedagógica, com ênfase na abordagem qualitativa. As técnicas empregadas foram observação, registro em diário de campo, vídeo e avaliação escrita. O projeto promoveu participação e interesse dos estudantes por práticas corporais diversificadas e integração entre meninos e meninas, apontando para a relevância dessa abordagem na escola.

Palavras chave: Educação física. Práticas corporais. Escola.
\end{abstract}

\section{Educação física e a tematização das práticas corporais}

Na década de 1980, a educação física passou por um processo de crítica de suas práticas no ambiente escolar, bem como de seu papel acadêmico na produção do conhecimento. Esse ficou conhecido como "movimento renovador", a partir do qual se apresentaram outras perspectivas teórico-metodológicas de trato pedagógico do esporte, coerentes com intenções políticas emancipatórias (BRACHT, 1999; DAOLIO, 1998). No entanto, vemos que, mesmo tendo passado cerca de quarenta anos do início do processo de redemocratização do país, a pedagogia esportivista ainda se perpetua (ESCOBAR; TAFFAREL; SOARES, 2010). Em Brasília, uma pesquisa de campo realizada em escolas públicas de ensino médio, em 2011, observou que as aulas de educação física se concentram no ensino do esporte e, ainda, que sua prática busca predominantemente a aprendizagem do gesto técnico. Esse modelo repercute o paradigma de rendimento, amplamente divulgado nas mídias, e, segundo o autor, produz individualismo, preconceito de classe, discriminação de gênero, enfim, exclusão e violência (BEHMOIRAS, 2011).

Por outro lado, o esporte ocupa espaço legítimo na educação física e deve ser tratado pedagogicamente como parte de seus conteúdos, ao se considerar que integra os conhecimentos constituintes da cultura corporal e a própria cultura dos estudantes (KUNZ, 
2010). O esporte, por conseguinte, caracteriza-se como um fenômeno polissêmico, o que nos instiga a revisitá-lo (ASSIS, 2001; SOUZA JÚNIOR, 2001). Além disso, ampliar o acesso a outras práticas corporais pertencentes ao universo de conteúdos da disciplina educação física pode contribuir para a construção de projetos político-pedagógicos das instituições de ensino, em perspectiva crítica.

Desse modo, realizou-se uma pesquisa pedagógica em uma instituição da rede pública do Distrito Federal, por meio de um projeto orientado pelo conceito de "práticas corporais". As aulas de educação física dessa instituição eram, de modo geral, restritas a atividades esportivas sob abordagem competitivista (GHIRALDELLI JÚNIOR, 2003). Essa característica repercutia no relacionamento entre os estudantes da turma, criando um ambiente de competitividade exacerbada e exclusão, o que dificultava sobremaneira as relações pedagógicas no processo de ensino-aprendizagem.

Como alternativa, a pesquisa baseou-se no conceito de práticas corporais, que se mostra uma abordagem em plena construção, dada a multiplicidade de fenômenos que as englobam. Esta se mostra uma área de estudos em processo de consolidação e muito se tem produzido a seu respeito, especialmente no campo da educação física (LAZZAROT TI FILHO et al., 2010). Esse conceito remete ao acervo de manifestações culturais construídas historicamente e expressas prioritariamente no âmbito do corpo (SILVA et al., 2009; LAZZAROTTI FILHO et al., 2010).

Vislumbra-se que no âmbito da educação física escolar, o conceito de práticas corporais pode levar a uma atividade educativa que aborda e considera diversas dimensões da vida humana. Considerando a cultura como elemento essencial da educação e as práticas corporais como manifestações culturais, o presente artigo buscou refletir sobre a abordagem desse universo em aulas de educação física na escola. Assim, este trabalho ${ }^{1}$ tem por objetivo analisar as "práticas corporais" como tema da educação física, por meio da proposição e discussão de um projeto pedagógico, junto a uma turma de oitavo ano de uma escola pública do Distrito Federal. O projeto valeu-se da problematização e vivência de esporte, dança e brincadeiras populares, à luz do conceito de "práticas corporais".

O estudo visa contribuir para a atualização da educação física escolar, diante dos desafios colocados pelo movimento renovador. Também representa um esforço de pesquisa, na direção de se pensar dialeticamente as relações entre a teoria e a prática no âmbito educacional (GERALDI; FIORENTINI; PEREIRA, 1998). A reflexão sistemática e a discussão pautada na documentação, por meio de observação e registro de experiências vividas na escola, constituem um bom recurso para compreender as relações sociais que são construídas nesse ambiente, apontando para outras possibilidades de abordagem do corpo nas aulas de educação física (BUSS-SIMÃO; FIAMONCINI, 2013).

Nas páginas que se seguem é apresentado o delineamento metodológico que orientou o processo investigativo. A partir da ação pedagógica desenvolvida, evidenciam-se e analisam-se as práticas corporais como tema para um projeto de educação física. Final-

1

O presente trabalho não contou com apoio financeiro de nenhuma natureza.

Pensar a Prática, Goiânia, v. 17, n. 4, out./dez. 2014 
mente, são feitas considerações baseadas na análise da ação pedagógica, destacando a escola como lugar de construção e apropriação da cultura do corpo.

\section{Delineamento metodológico}

Para o alcance do objetivo do trabalho, foi desenvolvida uma pesquisa pedagógica, com ênfase na abordagem qualitativa, levando em conta pressupostos de Lankshear e Knobel (2008). De acordo com os autores, a sala de aula é um lócus privilegiado desse tipo de pesquisa, embora não seja o único. Sobretudo, a pesquisa pedagógica "não é simplesmente uma questão de 'buscar algo que funcione', mas de ter como propósito entender por que este algo funciona e como funciona, pensar sobre onde pode ou não funcionar, e por quê" (LANKSHEAR; KNOBEL, 2008, p. 19). Sob essa visão, o apoio da teoria se torna um elemento fundamental que propicia análises mais consistentes e ainda um resultado mais abrangente.

A pesquisa foi realizada no segundo semestre de 2010, motivada originalmente pelo interesse de uma professora da rede pública de ensino, que procurou apoio em uma instituição universitária, mais especificamente em um grupo de pesquisa que se dedica a estudos da área de educação física escolar. Estabeleceu-se, assim, uma parceria entre a esfera acadêmica e a instituição escolar. O projeto foi amplamente discutido com a professora da escola, que contribuiu significativamente para o seu desenvolvimento, tendo ela participado de todas as etapas da investigação. Ressalte-se que, tal como proposto por Lankshear e Knobel (2008, p. 17), “o ponto crucial é que os propósitos ou os objetos da pesquisa pedagógica devem fluir de questões, problemas ou preocupações autênticos (ou percebidos) pelos próprios professores".

O trabalho foi desenvolvido por meio de um projeto para a disciplina educação física, no âmbito de uma turma de oitavo ano de uma escola pública do Distrito Federal, localizada em região periférica de Brasília-DF. De acordo com Hernández e Ventura (2009), pode organizar-se um projeto pedagógico seguindo um determinado eixo, nesse caso, uma temática. O projeto permite uma previsão das ações educativas, bem como dá funcionalidade ao que se deve aprender, relacionando procedimentos e diferentes alternativas organizativas aos temas a serem abordados.

O projeto enfocou a vivência de práticas corporais, especialmente esporte, dança e brincadeiras populares, e foi efetivado ao longo de seis semanas, ocupando seis aulas de observação e seis aulas de intervenção, com duração de cinquenta minutos cada uma delas. As práticas corporais foram realizadas na quadra esportiva, bem como em sala de aula. Demandaram o uso de poucos recursos didáticos, como bola de handebol, aparelho de som, papel, lápis e borracha. As informações produzidas a partir da proposição de práticas corporais junto ao grupo participante foram registradas por meio de diário de campo, vídeos das aulas e avaliação escrita por parte dos estudantes.

Buss-Simão e Fiamoncini (2013) apontam para a importância da observação e análise do ambiente escolar para que, a partir das indicações e indagações geradas nesse processo, se elabore um planejamento que atenda às demandas específicas e às situações significativas do contexto. O projeto pedagógico em tela partiu da observação de aulas de educação física. A turma era composta de trinta e dois estudantes, de ambos os sexos. A 
maioria dos estudantes tinha idade entre treze e quatorze anos. No entanto, também havia estudantes com doze, quinze e até mesmo dezesseis anos, o que reflete a diferença de idade que pode ser encontrada em turmas de anos finais do ensino fundamental de escolas públicas de Brasília, especialmente de regiões periféricas, provocada por casos de reprovação e evasão.

Durante a observação, constatamos que as aulas de educação física dessa turma se concentravam em esportes, especialmente o futebol. A maior parte dos meninos demonstrava habilidades motoras desenvolvidas e participava das atividades esportivas com autonomia. Seu desempenho era marcado por um forte traço competitivo e frequentemente eles se referiam ao esporte realizado no âmbito profissional. As meninas, por sua vez, demonstravam certa dificuldade na atuação em práticas esportivas. Algumas delas, mesmo assim, manifestavam desejo de participar das atividades, o que nem sempre ocorria, pois os meninos insistiam em dominar a quadra. Outras pareciam preferir o tempo livre para conversar ou jogar futebol de mesa, conhecido entre o grupo participante como "totó". Nesse cenário, observou-se, além dos esquemas de conhecimento precedentes dos alunos, que as aulas de educação física eram marcadas pela dificuldade de integração entre meninos e meninas. Embora esse panorama fosse semelhante em várias turmas, para esta análise optou-se pelo grupo que demonstrava maior receptividade ao diálogo, comportamento colaborativo nas atividades em geral e participação nas aulas de educação física.

\section{As práticas corporais como perspectiva da educação física}

Organizou-se a exposição e análise do projeto em ação, seguindo a sua própria estrutura de desenvolvimento didático na escola. Para orientar a análise salientaram-se as seguintes categorias, elaboradas a posteriori: "participação", "respostas dos estudantes às práticas corporais" e "gênero". A participação refere-se à adesão e ao envolvimento dos estudantes durante as vivências de práticas corporais propostas no projeto. As respostas dos estudantes às práticas corporais, por sua vez, referem-se à avaliação dos estudantes ao projeto, tanto durante o seu percurso quanto ao fim. A relação de gênero durante as aulas evidenciou-se como um aspecto significativo do processo, merecendo, assim, uma análise especial.

\section{a) Debate e integração}

A primeira aula foi iniciada com uma apresentação e discussão do projeto junto aos estudantes, destacando-se as atividades, o cronograma das aulas e a forma de avaliação. Pretendia-se criar entre os participantes uma atitude favorável ao conhecimento a ser abordado nas aulas, conforme sugerem Hernández e Ventura (2009). No entanto, de modo geral, a turma demonstrou uma leve resistência à ideia. Isso não surpreende, pois o projeto representa uma mudança de rotina da cultura escolar. Essa reação, contudo, não impediu sua efetivação, como veremos a seguir.

$\mathrm{Na}$ continuação da aula, propôs-se um debate acerca da educação física na escola. Objetivou-se problematizar as expectativas dos estudantes em relação à disciplina, bem 
como lançar as primeiras reflexões sobre a dificuldade de integração entre meninos e meninas, registrada no período de observação.

Considerando essa observação inicial, abordou-se a concentração de conteúdos das aulas em esportes, especialmente o futebol. Ao longo do debate, a maioria dos estudantes demonstrou, em suas falas, preferência pela prática do esporte, de acordo com conformações competitivas, como conteúdo da educação física. Esse tipo de expectativa repercute a tendência competitivista, anteriormente assinalada (GHIRALDELLI JÚNI$\mathrm{OR}, 2003)$. Nesse sentido, uma crítica tem sido feita à cultura esportiva presente na escola, construída sob a sombra do esporte de rendimento e sob a primazia do disciplinamento e desenvolvimento motor (BRACHT, 2009; KUNZ, 2010). Segundo os autores, a cultura corporal baseada no desempenho tende a gerar competição exacerbada, obsessão pela vitória e exclusão, em vez de integração. Nessa concepção de educação do corpo, que se consolidou na educação física brasileira, se afirmam a individualização e o afastamento, orientados pela busca da performance esportiva.

O debate inclinou-se para a questão da integração entre meninos e meninas, durante a vivência conjunta de práticas corporais. Outrossim, evidenciou-se uma representação tradicional por parte dos estudantes, ou seja, a de que há práticas corporais particulares para cada um dos gêneros, com poucas possibilidades de cooperação entre meninos e meninas nas aulas de educação física. De acordo com Saraiva (2005), as aulas de educação física, como se configuram na atualidade, privilegiam culturas de movimento diferenciadas para cada gênero, pois suas práticas, permeadas de representações sociais e normas de conduta, afirmam discriminações de gênero. Essas culturas distintas promovem o distanciamento físico e social entre meninos e meninas, pois não admitem as mesmas possibilidades para ambos os gêneros, promovendo, assim, hierarquização.

Os meninos indicaram o baixo nível de habilidades motoras das meninas e essas, por sua vez, indicaram a intolerância e a agressividade dos meninos, como principais obstáculos à prática conjunta. Segundo Pereira e Mourão (2005), as crianças tendem a considerar que as meninas atrapalham os meninos e eles, em contrapartida, atrapalham aquelas. As autoras apontam que não há uma harmonia nas práticas corporais envolvendo meninos e meninas e o elemento primordial apresentado seria a violência manifestada nos jogos e nas brincadeiras, sobretudo por meninos.

Tendo em vista as questões levantadas no debate, na segunda aula, também realizada em sala, propusemos uma dinâmica de integração da turma. Essa prática foi realizada com o objetivo de estreitar os laços entre os estudantes e estabelecer um ambiente propício ao trato pedagógico de práticas corporais na escola.

Distribuídos em grupos de três, compostos por ambos os gêneros, eles foram incentivados a conversar durante um período de dois minutos sobre quaisquer assuntos de seu interesse. Inicialmente, todos estavam dispostos em filas paralelas e deveriam se apresentar e cumprimentar os colegas. Elaboramos um roteiro de perguntas como sugestão para gerar o diálogo: "Qual a sua idade?", "Onde mora?", "Quantos irmãos têm?” e "O que gosta de fazer nas horas vagas?" Ao término de dois minutos, os trios se revezavam de forma a ampliar a interação da classe.

Observou-se que, apesar de pertencerem à mesma turma e compartilharem cotidianamente o mesmo espaço, a maioria dos estudantes demonstrou certa dificuldade de iniciar um diálogo com os colegas. Ao final da aula, os estudantes reconheceram que 
há distâncias não físicas e barreiras de comunicação intragrupo. Além disso, para eles, a educação física representa espaço de socialização e fortalecimento das relações entre estudantes e entre esses e o professor.

Sob essa perspectiva, Saraiva (2005) considera que a vivência de práticas corporais diversificadas na escola pode promover a aproximação respeitosa dos corpos e propiciar a interação física e psicológica dos estudantes, que se caracterizam como dimensões peculiares à experiência corporal. As práticas no âmbito do corpo podem permitir que 0 toque e o contato corporal, permeados de preconceito em nossa sociedade, sejam compreendidos e desmistificados por meio de vivências amplas e significadas por outros valores, que não os gerados pela competição e performance.

\section{b) Esporte na perspectiva das práticas corporais}

Conforme anteriormente observado, a maioria dos estudantes demonstrou preferência pela prática do esporte, de acordo com conformações competitivas. No entanto, pelo conceito de práticas corporais, os esportes devem ser pensados para além da espetacularização, competitividade e performance. De outro modo, devem superar a execução normatizada de movimentos e possibilitar a expressão e a promoção do cuidado de si, do bem-estar, da autoestima, da sociabilidade e da ludicidade, que são elementos fundamentais da experiência humana (SILVA; DAMIANI, 2005).

A terceira aula do projeto teve como objetivo específico proporcionar uma vivência diferenciada do esporte de rendimento. Tendo em vista os diferentes níveis de habilidades motoras e técnicas demonstradas pelos estudantes durante o período de observação, optamos pela prática do handebol, na quadra esportiva. Essa modalidade, ressalve-se, era pouco praticada pelo grupo. No entanto, utiliza, predominantemente, habilidades motoras básicas, como saltar, correr, arremessar, além das suas combinações. Entendemos que isso poderia motivar e proporcionar a participação de um número maior de estudantes no jogo (TENROLER, 2004).

Preliminarmente, o esporte foi praticado segundo as regras oficiais. Logo, observamos a tendência ao modelo de alto rendimento, que se caracterizou pela competitividade entre alguns, pelos gestos e comemorações que simulavam os de grandes atletas, bem como pela marginalização dos menos habilidosos durante as jogadas, em sua maioria, as meninas. Esse quadro, todavia, levou à proposição de modificações às regras do jogo, adaptando-as para que todos participassem.

Em intervalos, os estudantes eram reunidos e desafiados a pensar em estratégias que envolvessem a participação ativa de todos os integrantes da turma. Duas estratégias foram aplicadas nessa direção. A primeira exigia que um número mínimo de passes fosse realizado entre os jogadores de cada time, antes de se efetivar o arremesso a gol, o que gerou maior tempo de troca de bola e, por conseguinte, maior envolvimento da turma. Além dessa, o drible foi eliminado como recurso das jogadas, levando-os a passar mais a bola entre si e estabelecer um ambiente coletivo de jogo. Desse modo, efetivou-se uma aprendizagem a partir da diversidade e não da ênfase nas características ou deficiências dos participantes, aspecto relevante da metodologia de projetos (HERNÁNDEZ; VENTURA, 2009).

Pensar a Prática, Goiânia, v. 17, n. 4, out./dez. 2014 
O jogo mediado por regras integradoras, mobilizou meninos e meninas, que fizeram apontamentos positivos acerca dessa vivência. A maioria demonstrou satisfação em participar da prática, mesmo que não tenham evidenciado ótimo desempenho técnico, perfeição do gesto motor e habilidades apuradas para o esporte em questão. Alguns estudantes, no entanto, declararam preferir a vivência do esporte, de acordo com regras oficiais. As estratégias abordadas não foram percebidas pelos participantes da mesma forma, revelando que as metodologias elencadas nem sempre são eficientes para todos. Por essa razão, o professor deve identificar e testar diferentes métodos e formas de envolver seus estudantes, tendo em vista seus objetivos e concepções pedagógicas (MARTINS; FREIRE, 2013).

\section{c) Dança e brincadeiras populares}

De forma a valorizar a multiplicidade de práticas corporais como conteúdo escolar, a quarta e quinta aulas do projeto tiveram como tema "dança" e "brincadeiras populares", respectivamente. Objetivou-se ampliar a vivência de práticas alternativas ao esporte, enfatizando outros elementos da cultura, que também integram o acervo de conteúdos da educação física.

No projeto em tela, a dança foi elencada por representar a cultura, as crenças e os saberes populares e por favorecer, por meio de gestos, músicas e ritmos, a ampliação das técnicas corporais, o aprendizado em grupo, a convivência e a cooperação (BARBOSARINALDI; LARA; OLIVEIRA, 2009). Essa prática se caracteriza como uma forma de comunicação e expressão social e se destaca por valorizar o desenvolvimento de habilidades rítmicas e a aproximação corporal (SOUSA; CARAMASCHI, 2011).

Para a aula de dança, contou-se com a colaboração de um professor convidado com expertise nessa prática. $\mathrm{O}$ estilo de dança explorado foi o forró, embora a maioria dos estudantes tenha afirmado pouco conhecer, como também não gostar desse estilo. Inicialmente, fez-se uma breve incursão sobre as origens do forró, suas variações e características culturais, buscando relacioná-lo com outros estilos musicais, mais conhecidos por parte da turma. No segundo momento da aula, todos foram convidados à prática do forró. Foram vivenciados passos básicos, noções de ritmo e coordenação motora, individualmente.

Em seguida, passou-se à movimentação em pares. Treze estudantes, proporcionalmente divididos por sexo, se disponibilizaram para participar dessa aula, enquanto os demais se limitaram a observar. As meninas demonstraram maior interesse em aprender e participar da dança do que os meninos. Observou-se que a formação de pares se mostrou uma dificuldade para a maioria, o que levou alguns a deixarem a atividade no seu transcorrer. A dança demanda ação conjunta de qualidades distintas, que se revelam nos papéis da dama e do cavalheiro. O exercício de habilidades variadas e a relação entre os pares, estabelecida na dança, são oportunidades de desenvolver uma cultura de respeito às diferenças, que questiona a premissa de que determinadas práticas e habilidades motoras cabem exclusivamente a determinado gênero, colaborando com a iniciativa de construir uma concepção de educação crítica quanto a preconceitos e conformações sociais (SARAIVA, 2005).

Pensar a Prática, Goiânia, v. 17, n. 4, out./dez. 2014 
Ao término da aula, o professor fez uma demonstração da dança, em nível mais avançado, aplicando alguns dos conhecimentos ensinados anteriormente. A dança, mais especificamente o forró, como conteúdo da educação física causou uma avaliação positiva entre os estudantes. Com poucas exceções, eles expressaram opiniões favoráveis a respeito da atividade, seja pela possibilidade de aprender a dominar o estilo ou pelo caráter inovador da proposta. Mesmo os estudantes que não participaram ativamente da aula apreciaram a oportunidade, como evidenciam os depoimentos a seguir.

Participei de quase todas as aulas, menos da dança, se bem que eu queria dançar, mas eu morro de vergonha (Menina, 14 anos).

Adorei. Principalmente a aula de forró. Não dancei, mas ri muito (Menino, 13 anos).

A breve contextualização da dança e sua aproximação com a cultura dos participantes favoreceram a identificação e ajudaram a ampliar a aceitação dos estudantes diante da nova experiência. Estabelecer relações entre os sujeitos e os saberes próprios da prática mostra-se uma estratégia relevante na construção do processo educativo, especialmente na introdução de atividades ainda pouco exploradas na educação física escolar, como a dança (KLEINUBING et al., 2012).

$\mathrm{Na}$ aula seguinte, foram tematizadas brincadeiras populares. Como práticas corporais, as brincadeiras populares caracterizam a expressão da cultura e são, em sua maioria, de fácil realização, pois utilizam fundamentalmente o corpo como recurso e instrumento. Seus gestos, cantos, rodas e mímicas revelam as crenças, os saberes e as representações construídas pelo povo, de forma que, como conteúdo da educação física, mostram-se significativas para ressaltar a historicidade humana. Não obstante, são práticas que propiciam a ampliação das técnicas corporais, favorecem o aprendizado em grupo, a cooperação, a convivência com o outro e o acesso à cultura em que se encontram inseridos os sujeitos (BARBOSA-RINALDI, LARA; OLIVEIRA, 2009).

Em continuidade à vivência de práticas corporais diversificadas, propôs-se a brincadeira popular "Coelho sai da toca". Houve resistência no início da aula por parte dos estudantes, pois eles argumentaram que aquela não era uma atividade condizente com suas idades e que "preferiam jogar bola". Apesar disso, a turma concordou em participar da proposta, exceto um deles. No transcorrer da aula, aos poucos eles se envolveram com a brincadeira, o que também contagiou aquele que tinha ficado de fora no início. Interessante registrar que modificações foram sugeridas durante a brincadeira e, desse modo, os participantes deram suas próprias contribuições, que foram aceitas e incorporadas à atividade. Uma das sugestões era cumprimentar três colegas ou abraçar um colega antes de encontrar uma nova "toca". Tais adaptações aumentaram o grau de dificuldade. Sobretudo, impuseram desafios aos estudantes, entre os quais a transposição de barreiras de comunicação intragrupo, identificadas na primeira aula do projeto. Embora, inicialmente, não tenha sido plenamente recebida, os discentes declararam, em avaliação, que apreciaram a vivência da brincadeira, qualificando-a como "divertida", o que ficou evidente pelo envolvimento do grupo.

Junto aos sujeitos pesquisados, a brincadeira popular mostrou-se, em adição, uma forma de propiciar a integração entre meninos e meninas. Não obstante a grande aproxi- 
mação corporal que essa prática exige, a brincadeira foi vivenciada sem os conflitos de gênero, geralmente observados e apontados pelos estudantes na primeira aula do projeto. Possibilitou também que os estudantes participassem da construção da vivência, uma vez que as brincadeiras populares não estão submetidas a normas rígidas ou modelos de rendimento. Ademais, parecem favorecer o desenvolvimento de outras habilidades físicas e sociais, que não aquelas priorizadas nos esportes, estabelecendo novas relações entre os sujeitos (BARBOSA-RINALDI, LARA; OLIVEIRA, 2009).

\section{d) Avaliação participativa}

Ao término do projeto pedagógico os estudantes redigiram um texto avaliativo registrando suas percepções acerca do processo. No que diz respeito à receptividade, inicialmente, houve alguma resistência à vivência de práticas corporais diversificadas nas aulas de educação física, pois a principal referência para a disciplina ainda é o esporte sob abordagem competitivista. Isso se evidenciou no discurso de um aluno que não conseguiu estabelecer vínculos entre dança e educação física na escola.

Isso é aula de educação física ou é aula de dança? (Menino, 15 anos).

O esporte é o elemento da cultura corporal mais expressivo no cotidiano dos estudantes e se faz presente por meio de diversas instituições sociais, destacadamente a mídia (BETTI, 1998; PIRES, 2002). A exposição midiática, os programas de formação de atletas voltados ao público escolar e a tradição da disciplina contribuem para localizar o interesse dos estudantes pelo fenômeno esportivo de alto nível e reforçam uma concepção de educação física baseada na visão esportivista (BRACHT, 2009).

Em contrapartida, ao longo do desenvolvimento do projeto, os estudantes se mostraram receptivos a uma ação pedagógica pautada em problematização e vivência de práticas corporais. Em avaliação, apontaram a diversidade das práticas como aspecto positivo e revelaram apreciar a possibilidade de vivenciá-las nas aulas.

Eu gostei muito das aulas porque as professoras passaram coisas diferentes. Cada aula foi mais legal (Menino, 13 anos).

A professora tentou fazer atividades mais dinâmicas e não aquela professora que só leva prá quadra e passa texto (Menina, 12 anos).

As professoras animaram nossa turma, porque estamos cansadas dessas aulas chatinhas que temos (Menina, 13 anos).

Cabe destacar que o tratamento dado aos conteúdos interferem diretamente no interesse dos estudantes. Para que se apreenda o conhecimento ofertado pelo professor é fundamental que se criem condições para sua transmissão e assimilação, não bastando aplicá-lo genericamente a um universo qualquer de estudantes (DAOLIO, 1995). Os conteúdos devem adequar-se às peculiaridades e às necessidades apresentadas por cada grupo, sob o risco de serem ministradas aulas improdutivas do ponto de vista da aprendizagem significativa.

Pensar a Prática, Goiânia, v. 17, n. 4, out./dez. 2014 


\title{
Considerações finais
}

Neste estudo buscou-se abordar as "práticas corporais" como tema da educação física, por meio da proposição e discussão de um projeto pedagógico, junto a uma turma de oitavo ano de uma escola pública do Distrito Federal. Observou-se que, inicialmente, a turma demonstrou certa resistência à proposta. Contudo, ao longo do processo essa resistência se tornou envolvimento e participação ativa nas aulas. A abordagem de conteúdos nas aulas de educação física sob o conceito de práticas corporais superou a execução normatizada dos movimentos em dança, esportes e brincadeiras populares ao promover expressão, sociabilidade e ludicidade, gerando aproximação com a cultura dos estudantes e interesse deles pelas práticas.

O caráter diversificado das práticas corporais favoreceu o contato e a interação entre os estudantes e permitiu ampliar a integração entre meninos e meninas. Desse modo, as aulas pautadas na vivência de práticas corporais diversificadas mostraram-se espaço privilegiado às discussões e aprendizados envolvendo relações interpessoais.

Apesar do curto período de duração do projeto em tela, as análises engendradas levam-nos ao entendimento de que as práticas corporais como tema da educação física mostraram-se legítimas, oferecendo inúmeras possibilidades educativas à disposição dos professores. Para isso, no entanto, as práticas corporais efetivadas no âmbito da escola precisam ser consideradas como a expressão de uma manifestação que reflete valores e significados presentes na sociedade. Para além desse entendimento, é preciso considerar que essas práticas possibilitam o desenvolvimento do sujeito a partir do conjunto de experiências que se constroem no corpo, a partir do corpo e por meio do corpo (SILVA; DAMIANI, 2005).

Nesse sentido, a documentação, a observação e o registro do fazer pedagógico mostram-se significativos instrumentos de análise pedagógica e construção de novas propostas educativas no âmbito da educação física (BUSS-SIMÃO; FIAMONCINI, 2013). A análise e discussão de experiências pedagógicas realizadas em contextos específicos contribuem com aqueles que buscam convergências no que concerne às formas de educar e de pensar a educação em vias alternativas. Acreditamos que as reflexões aqui apresentadas podem vir a oferecer caminhos para o trato das práticas corporais na escola.

\section{“THAT'S PHYSICAL EDUCATION CLASS?" BODY PRACTICES IN SCHOOL}

\begin{abstract}
The goal of the present study was to analyze "body practices", as theme to school physical education, through the proposal and discussion of a pedagogical project with an eighth-grade class in a public school of the Federal District. The project was based on the problematization and experience of sports, dances, and popular games, in the light of the concept of body practices. The methodology was based on elements of educational research, with an emphasis on qualitative ap proach. The techniques employed were observation, field notes, video and written evaluation. The project promoted student interest and participation by diverse body practices and integration between boys and girls, pointing to the relevance of this approach in school.
\end{abstract}

Keywords: Physical Education. Body practices. School. 


\title{
"ESO ES CLASE DE EDUCACIÓN FÍSICA?" PRÁCTICAS DE CUERPO EN LA ESCUELA
}

\begin{abstract}
Resumen
El presente estudio tuvo por objetivo analizar las "prácticas corporales", como tema de la educación física escolar, a través de la propuesta y discusión de un proyecto pedagógico con alumnos de octavo grado de una escuela pública del Distrito Federal. El proyecto se basó en la problematización y la experiencia de deportes, danzas y juegos populares, teniendo en cuenta el concepto de prácticas corporales. La metodología se basa en los elementos de la investigación educativa, con énfasis en el enfoque cualitativo. Las técnicas empleadas fueron la observación, diario de campo, el video y la evaluación escrita. El proyecto promovió el interés del estudiante y la participación de diversas prácticas corporales y la integración entre niños y niñas, que apunta a la relevancia de este enfoque en la escuela.
\end{abstract}

Palabras-claves: Educación Física. Prácticas corporales. Escuela.

\section{Referências}

ASSIS, S. Reinventando o esporte: possibilidades de prática pedagógica. Campinas: Papirus, 2001.

BARBOSA-RINALDI, I. P.; LARA, L. M.; OLIVEIRA, A. A. B. Contribuições ao processo de (re)significação da educação física escolar: dimensões das brincadeiras populares, da dança, da expressão corporal e da ginástica. Movimento, Porto Alegre, v. 15, n. 4, p. 217-242, out./dez. 2009.

BEHMOIRAS, D. C. Educação física escolar e sua interface com o esporte e a mídia. 2011. 149 f. Dissertação (Mestrado em Educação Física) - Faculdade de Educação Física, Universidade de Brasília, Brasília, 2011.

BETTI, M. A janela de vidro: esporte, televisão e educação física. Campinas: Papirus, 1998.

BRACHT, V. A constituição das teorias pedagógicas da educação física. Cadernos Cedes, Campinas, v. 19, n. 48, p. 69-88, ago. 1999.

. Esporte de rendimento na escola. In: STTIGER, M. P.; LOVISOLO, H. (Org.). Esporte de rendimento e esporte na escola. Campinas: Autores Associados, 2009. p. 11-27.

BUSS-SIMÃO, M.; FIAMONCINI, L. Educação física na educação infantil: reflexões sobre a possibilidade de trabalhos com projetos. Revista Pensar a Prática, Goiânia, v. 16, n. 1, p. 131-139, jan./mar. 2013. 
DAOLIO, J. A construção do corpo feminino ou o risco de se transformar meninas em "antas". In: ROMERO, E. (Org.). Corpo, mulher e sociedade. Campinas: Papirus, 1995. p. 99-108. pirus, 1998.

Educação física brasileira: autores e atores da década de 1980. Campinas: PaESCOBAR, M.; TAFFAREL, C.; SOARES, C. A educação física escolar na perspectiva do século XXI. In: MOREIRA, W. W. (Org.). Educação física \& esportes: perspectivas para o século XXI. 16. ed. Campinas: Papirus, 2010.

GERALDI, C. M. G.; FIORENTINI, D.; PEREIRA, E. M. de A. (Org.). Cartografias do trabalho docente: professor(a)-pesquisador(a). Campinas: Mercado de Letras; Associação de Leitura do Brasil, 1998. 336 p.

GHIRALDELLI JÚNIOR, P. Educação física progressista: a pedagogia crítico-social dos conteúdos e a educação física brasileira. 8. ed. São Paulo: Loyola, 2003.

HERNÁNDEZ, F.; VENTURA, M. Organização do currículo por projetos de trabalho. Porto Alegre: Artmed, 2009.

KLEINUBING, N. D. et al. A dança na perspectiva crítico-emancipatória: uma experiência no contexto do ensino médio. Revista Pensar a Prática, Goiânia, v. 15, n. 3, p. 711728, jul./set. 2012.

KUNZ, E. Transformação didático pedagógica do esporte. 7 ed. Ijuí: Unijuí, 2010.

LANKSHEAR, C.; KNOBEL, M. Pesquisa pedagógica: do projeto à implementação. Porto Alegre: Artmed, 2008.

LAZZAROTTI FILHO, L. A. et al. O termo práticas corporais na literatura científica brasileira e sua repercussão no campo da educação física. Movimento, Porto Alegre, v. 16, n. 1, p. 11-29, jan./mar. 2010.

MARTINS, A. B. R.; FREIRE, E. S. O envolvimento dos alunos nas aulas de educação física: um estudo de caso. Revista Pensar a Prática, Goiânia, v. 16, n. 3, p. 760-774, jul./set. 2013.

PEREIRA, S. M.; MOURÃO, L. Identificações de gênero: jogando e brincando em universos divididos. Motriz, Rio Claro, v. 11, n. 3, p. 205-210, set./dez. 2005.

PIRES, G. de L. Educação física e discurso midiático: abordagem crítico-emancipatória. Ijuí: Unijuí, 2002.

Pensar a Prática, Goiânia, v. 17, n. 4, out./dez. 2014 
SARAIVA, M. C. Co-educação física e esportes: quando a diferença é mito. Ijuí: Unijuí, 2005.

SILVA, A. M. et al. Corpo e experiência: para pensar as práticas corporais. In: FALCÃO, J. L. C.; SARAIVA, M. C. (Org.). Práticas corporais no contexto contemporâneo: (in) tensas experiências. Florianópolis: Copiart, 2009. p. 10-27.

SILVA, A. M.; DAMIANI, I. R. As práticas corporais na contemporaneidade: pressupostos de um campo de pesquisa e intervenção social. In: SILVA. A. M; DAMIANI, I. R. (Org.). Práticas corporais: gênese de um movimento investigativo em educação física. Florianópolis: Nauemblu Ciência \& Arte, 2005. p. 17-28.

SOUSA, N. P. C.; CARAMASCHI, S. Contato corporal entre adolescentes através da dança de salão na escola. Motriz, Rio Claro, v. 17, n. 4, p. 618-629, out./dez. 2011.

SOUZA JÚNIOR, M. A Educação Física no currículo escolar e o esporte: (im)possibilidade de remediar o recente fracasso esportivo brasileiro. Revista Pensar a Prática, Goiânia, v. 4, p. 19-30, jun. 2001.

TENROLER, C. Handebol: teoria e prática. Rio de Janeiro: Sprint, 2004.

Recebido em: 04/06/2014

Revisado em: 21/09/2014

Aprovado em: 07/10/2014

Endereço para correspondência:

leirianegregorio@hotmail.com

Leiriane Viveiros Gregório

Universidade de Brasília, UNB - Campus Darcy Ribeiro.

Campus Darcy Ribeiro

Asa Norte

70910900 - Brasília, DF - Brasil 